\title{
Undergraduate basic sciences and engineering students' understanding of the concept of derivative
}

\author{
Saeid Haghjoo, Ebrahim Reyhani \\ Faculty of Science, Shahid Rajaee Teacher Training University, Islamic Republic of Iran \\ *Corresponding author: s.haghjoo@sru.ac.ir
}

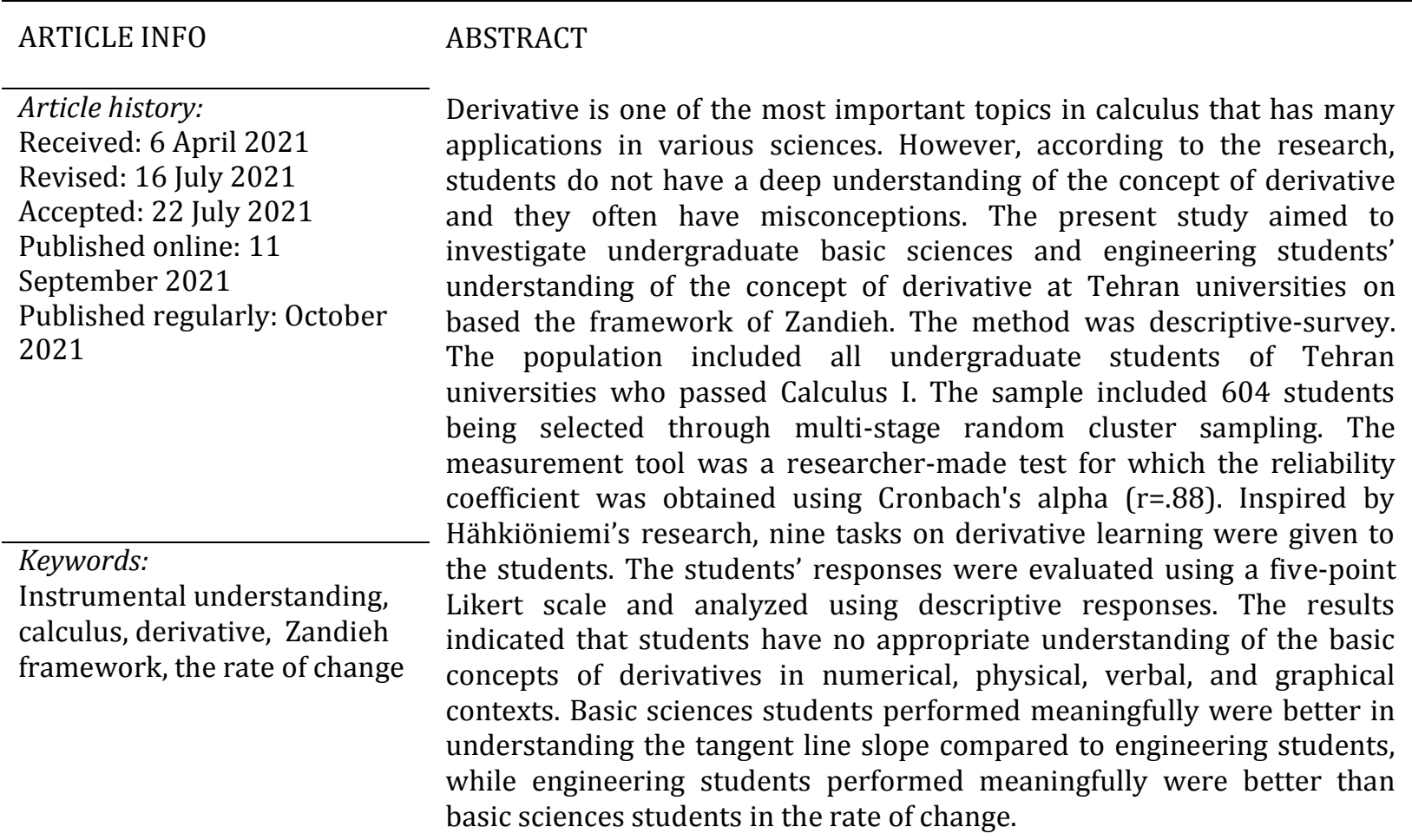

(C) 2021 Universitas Muhammadiyah Surakarta

\section{Introduction}

Researchers believe that calculus is one of the greatest achievements of human reason (NCTM, 2000; Hughes-Hallett et al., 2017). The concept of derivative is one of the most important topics in calculus and has applications in sciences such as economics (Feudel, 2019; Feudel \& Biehler, 2021). Derivatives are presented differently in math curricula in different countries. Such a concept is presented in the new mathematics textbooks of Iran in the $12^{\text {th }}$ grade, as well as the undergraduate curriculum of universities in the first year. Some studies show that understanding the concept of derivative is one of the most difficult concepts for students due to the complexity of its definition and representations (Thompson \& Thompson, 1996; Zandieh, 2000; Auxtero \& Callaman, 2020; Mirin, 2018). Many studies were conducted on students' thinking about the concepts of calculus including derivative (e.g., Berry \& Nyman, 2003; Oehrtman, 2009; Rivera-Figueroa \& Guevara-Basaldúa, 2019; Selden, Selden, Hauk \& Mason, 2000). The historical trend of

To cite this article:

Haghjoo, S., \& Reyhani, E. (2021). Undergraduate basic sciences and engineering students' understanding of the concept of derivative. JRAMathEdu (Journal of Research and Advances in Mathematics Education), 6(4), 277-298. https://doi.org/10.23917/jramathedu.v6i4.14093 
using derivative to its official definition took more than 200 years. First, it was used by Fermat, and then it was discovered by Newton and Leibniz. Finally, it was developed by Taylor, Euler, and Maclaurin. Accordingly, Lagrange named it, and finally Cauchy and Weierstrass defined derivative precisely (Desfitri, 2016 ; Jaafar \& Lin ,2017; Haghjoo, Reyhani, \& Kolahdouz, 2020). Derivative was studied by different methods as part of calculus (Heid, 1988; Zandieh, 1997, 2000; Likwambe \& Christiansen, 2008; Huang, 2011; Bingolbali, Monaghan, \& Roper, 2007; Weber, Tallman, Byerley, \& Thompson, 2012), ratio (Thompson \& Thompson; 1996; Confrey \& smith, 1994 , Byerley \& Thompson, 2017), dynamic simulation (Roschelle, Kaput, \& Stroup, 2000; Johnson, 2010 , Santos \& Thomas, 2003; Samuels, 2017), modeling (Ärlebäck, Dorer, \& O’Neil, 2013; English, 2008; Carli, Lippiello, Pantano, Perona \& Tormen, 2020), and teaching (Sánchez-Matamoros, Fernández, \& Llinares, 2019).

Zandieh (1997) indicated that the basic understanding leading to the concept of derivative is realized in various representations and tasks in the context of calculus that is called derivative conceptual understanding. Zandieh (2000) presented a framework for analyzing students' understanding of the concept of derivative. One component of this framework include multiple representations such as graphical, verbal, physical, and symbolic and the other one includes the contexts and layers of process-object pairs including ratio, limit, and function (Zandieh, 1997; 2000). Different models have been suggested in the mathematics education literature that aims at describing an understanding of the derivative concept such as concept image and concept definition (Tall \& Vinner, 1981), APOS (Action-Process-object-schema) (Asiala, Cottrill, Dubinsky, \& Schwingendorf, 1997), APOS-Traid (Intra-Inter-Trance) (Baker, Cooley, \& Trigueros, 2000), and APOS-ACE Action, Process, Object, and Schema-Activities, Classroom discussion, and Exercises) (Borji, Alamolhodaei, \& Radmehr, 2018). In the following, we want to describe one prominent models we have built our research on. A review of further models can be found in Feudel (2019). Based on our experiences, in teaching differential calculus, we observed problems in understanding the derivative. For this purpose, we sought to investigate the cause. Conducting studies on understanding the concept of derivative, we came to the conclusion that we should use Zandieh ( $\underline{2000})$ framework in the context of

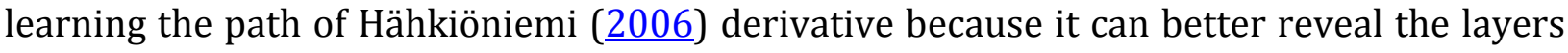
and contexts of the concept of derivative and 9 task designed. Hähkiöniemi On the basis of the analysis of the students' use of different kinds of representations, it was considered how these representations could be used in the learning of the derivative (2006). Model by Zandieh ( $\underline{2000})$, which is often used in mathematics education research at college level (Carlson et al. 2002; Hähkiöniemi 2006; Roorda, Vos, \& Goedhart, 2009; Likwambe \& Christiansen 2008; Roundy, Dray, Manogue, Wagner, \& Weber, 2015; Jones \& Watson 2017; Abd Hamid, Idris, \& Tapsir, 2019). She based her model on the construct of concept image by Tall and Vinner (1981). According to them, an understanding of a mathematical concept is not characterized by only knowing its concept definition. It is also characterized by the so-called concept image (p. 152): "The concept image represents the total cognitive structure associated with a concept which includes all the mental pictures and associated properties and processes."

The present study aims to investigate the undergraduate students' understanding of the concept of derivative at Tehran universities based on the framework of Zandieh ( $\underline{2000})$. Zandieh framework has been used in several articles. The two-dimensional table of layers and representations is the advantage of this framework over other frameworks. In this study, numerical representation has also been added to Zandieh framework. Accordingly, the following research questions were raised as follows: 
1. How is the Iranian engineering and basic sciences students' understanding of the concept of derivative?

2. How is the performance of Iranian engineering and basic sciences students in the layers of ratio, limit and function in the concept of derivative based on the framework of Zandieh?

3. How is the performance of Iranian engineering and basic sciences students in the contexts of graphical, physical, numerical, and verbal representations in the concept of derivative based on the framework of Zandieh?

\section{The framework of Zandieh for students' understanding of the concept of derivative}

Zandieh (1997) indicated that a fundamental understanding which leads to the concept of derivative is realized during different representations and tasks in the contexts of calculus. Process-object is one of the basic concepts in this framework being derived from Sfard's (2008) perspective in the previous section. The two main components of this framework include multiple representations (contexts) and layers of process-object pairs each of which is briefly described below. Multiple representations of the concept of derivative concept include: 1) graphical as the slope of tangent to curve at a point, 2) verbal as instantaneous rate of change, 3) Physical as velocity (acceleration and the general state of motion), and 4) Symbolic as the limit of difference quotients. The derivative layers which can play as a process and an object are as follows. Ratio is the process of dividing numerator by fraction. Object is considered as a pair of integers or the output of the division process. Limit is the process of approaching a value. Object is the limit value. Function is regarded as the process of the correspondence between two nonempty sets. Finally, object is a set of ordered pairs.

\section{The layers of Zandieh's framework for connecting the limits and derivatives}

Figure 1 illustrates the layers and processes between the limit and derivative and their relationship from Zandieh's perspective. If the conceptual structure of a student is not developed in one of the layer, Zandieh uses the pseudo-structural concept (Zandieh, 1997). Figure 1 illustrates the process of ratio which should be first perceived to understand the concept of derivative and its result is the difference quotient being turned into object. Then, the limiting process should then be formed, the result of which is an object derivative at one point, and in the third layer, the derivative is calculated at several points, the result of which is the derivative as function.

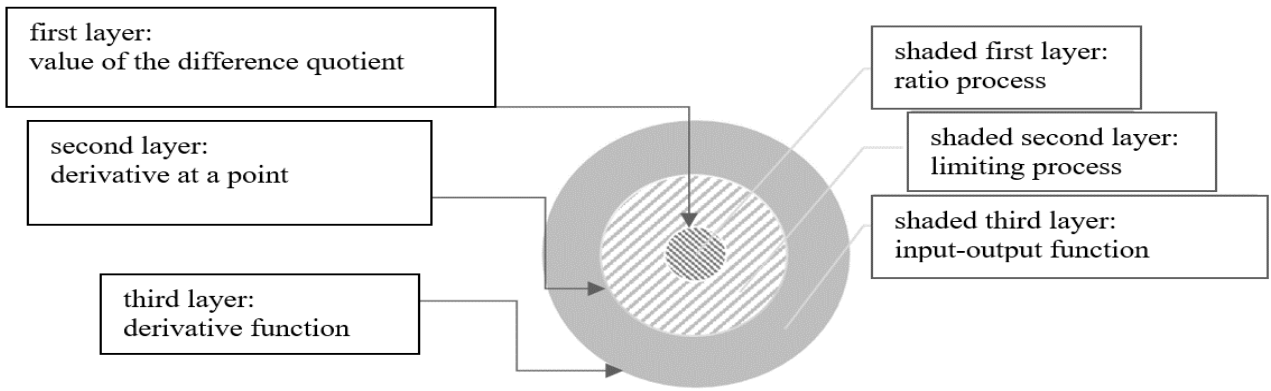

Figure 1. Illustration of connecting layers between limit and derivative based on Zandieh layers $(\underline{2000})$

It should be noted that verbal and pictorial representations are equally significant in making meaning (Cuoco \& Curcio, 2001).

\section{Expanded framework of Zandieh}

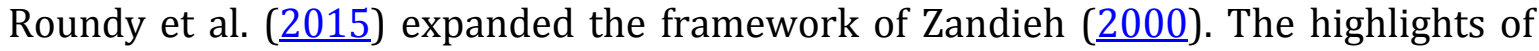
this framework include: 1) expanding physical representations to those interested in 
physics, 2) introducing the thickness idea for the approximate value of derivative [In physical and engineering problems, it is necessary for values to be highly close to zero for calculation, but $\Delta x=1$ can be also considered], and 3) adding a numerical context, 4) Adding an instrumental understanding row to the layers but in a completely separate table, for those who merely know the derivative formula, to reflect its weak relationships with the aspects of the derivative concept.

Table 1 shows the students' understanding of the Roundy et al.'s ( $\underline{2015})$ derivative. The column of numerical calculations and focus on its physical aspect are among the parameters of this framework. The instrumental comprehension row is also considered separately so that the layers of instrumental comprehension should be considered

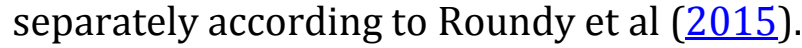

Table 1

Students' understanding of Roundy et al. (2015) derivative

\begin{tabular}{|c|c|c|c|c|c|}
\hline $\begin{array}{c}\text { Process-object } \\
\text { layer }\end{array}$ & Graphical & Verbal & Symbolic & Numerical & Physical \\
\hline & Slope & Rate of change & Difference quotient & Ratio of changes & Measurement \\
\hline & & & & $\underline{y_{2}-y_{1}}$ & \\
\hline Ratio & & $\begin{array}{l}\text { "Average rate of } \\
\text { change" }\end{array}$ & $\frac{f\left(x_{0}+\Delta x\right)-f\left(x_{0}\right)}{\Delta x}$ & $\begin{array}{l}\quad \overline{x_{2}-x_{1}} \\
\text { (ratio of of } \\
\text { change)Numeri } \\
\text { cally }\end{array}$ & \\
\hline Limit & & $\begin{array}{l}\text { "Instantaneous } \\
\text {..." }\end{array}$ & $\lim _{\Delta x \rightarrow 0} \quad \ldots$ & $\begin{array}{l}\ldots \quad \text { with } \triangle \mathrm{x} \\
\text { small }\end{array}$ & \\
\hline Function & & $\begin{array}{l}\text { “... at any } \\
\text { point/ime" }\end{array}$ & $f^{\prime}(x)=\cdots$ & $\begin{array}{l}\text {...depends on } x \\
\text { (a sequence of } \\
\text { numerical } \\
\text { ratios } \\
\text { differences of } \\
\text { aroundany } x \text { ) }\end{array}$ & $\begin{array}{l}\text { Tedious } \\
\text { repetition }\end{array}$ \\
\hline Function & & \multicolumn{4}{|c|}{$\begin{array}{l}\text { Symbolic } \\
\text { Instrumental understanding } \\
\text { Rules to 'take a derivative' }\end{array}$} \\
\hline
\end{tabular}

As shown in Table 1, the example provided for physical representation is derivative, where $\frac{d V}{d P}$ is the volume of an air-filled piston relative to the pressure on the piston, being controlled by a set of weights on the piston (In this example, a weight of 1 unit was used for the concept of thickness). Derivative can be considered as compressibility, velocity, thermal conductivity, etc (Gundlach \& Jones, 2015).

Hähkiöniemi ( $\underline{2006})$ stated that there are two paths for understanding the perceptual derivative, which is based on intuitive representations such as the steep slope of a function or the slip of a pencil between the function to the tangent line, as well as symbolic derivative, which is shown with difference quotients. Based on to Hähkiöniemi's derivative learning derivative, students usually learn with a motion context and learn the derivative through the tasks covering the visual and symbolic worlds together. In addition to the expanded framework of Zandieh, Hähkiöniemi's hypothesis was used in the tasks of this study. Hähkiöniemi derived his idea from Tall's three mathematical worlds of the visual world, symbolic world, and formal world (Tall, 2008). 


\section{Research Methods}

The present survey study had one test for evaluating the undergraduate basic sciences and engineering students' understanding of the concept of derivative at Tehran universities (9 Universities). The population included all students of Tehran universities studying in the fields of engineering and basic sciences (Farhangian University was also added) and passing calculus I. According to researchers, the reason is related to the students entering universities and prioritizing their majors. Based on the Ministry of Science, Research, and Technology, the number of undergraduate students in Tehran is 174,000. Basic science fields include mathematics and applications, computer science, chemistry, and physics. The students were studying during the academic year 2017-2018.

In the present study, participants were selected through multi-stage random cluster sampling and the maximum sample required in this study based on Morgan table was about 383 students, while 604 students were selected in this study. The test power was obtained as $80.3 \%$. The participants were selected from the students of Tehran universities. The selected universities are mostly the mother universities of the capital and most of its students are from all over the country. The sample students studied in different semesters (Mostly the first year of university) but the researchers targeted the students passing calculus I(Simple questions were posed from the concept of derivative). Table 2 indicates the number of students in each university separately.

Table 2

The number of students at universities (UE: Engineering students) (US: Basic sciences students)

\begin{tabular}{lllllllllll}
\hline University & UE1 & US2 & UE2 & UE3 & US4 & UE4 & US5 & UE6 & US7 & UE7 \\
\hline number & 13 & 57 & 64 & 25 & 36 & 21 & 51 & 21 & 14 & 102 \\
\hline University & US8 & US9 & US10 & US1 & US3 & UE5 & US6 & UE8 & Total & \\
\hline number & 22 & 52 & 35 & 18 & 22 & 17 & 18 & 16 & 604 & \\
\hline
\end{tabular}

In this study, a researcher-made test was designed based on the hypothesis of Hähkiöniemi's ( $\underline{2006})$ derivative learning path, and the framework was designed based on Table 1 since all representations were considered in the tasks, and in Physical layer, Velocity is considered.

\section{Data collection tool}

The researcher-made test was used to evaluate the students' understanding of the concept of derivative. The face validity and content validity of the test were confirmed. The reliability coefficient of the test was obtained by using Cronbach's alpha ( $\mathrm{r}=0.88)$, indicating the appropriate reliability of the test. In order to design the test questions, first the researchers examined the available references related to the concept of derivative and calculus books and selected 102 questions. After reviewing the questions based on Hähkiöniemi hypothetical learning path to the derivative (2006), their number reduced to 16 , and finally nine questions were approved for the experimental stage. The testing time was 25-35 minutes (Multiple choice questions without description). In the experimental stage, the questions were descriptive and took one hour to answer. In this stage students were write the reasons of choice. After analyzing the questions and the students' correct and incorrect answers, the questions were designed as multi-choice, so that the students could show their maximum ability and minimize mistakes. At the same time, the students were asked to present their own solutions.

\section{Data analysis method}

The students' answers were coded through a five-point Likert scale. The scores 0-4 were assigned to each choice of the task. Thus, the total test score was considered as a 
maximum of 32 (without task1), Task 1 has been analyzed only qualitatively and other tasks have been analyzed both quantitatively and qualitatively. Data analysis was performed using SPSS software version 24. After collecting the answers, the layers of ratio, limit and function and various contexts of tasks were analyzed quantitatively and qualitatively according to Zandieh framework.

\section{Results and Discussion}

First, nine tasks were analyzed quantitatively and qualitatively. Then, the results and findings were summarized and the questions were answered. Task 1 was descriptive, but the rest of the tasks were multiple choices. For this reason, it is not listed in Table 3 and task 1 will be explained below. The results of these findings can be important for teaching and learning of concept of derivative for university professors, teachers, textbook authors, and researchers.

Table 3

Descriptive table of the students' answers to the tasks

\begin{tabular}{|c|c|c|c|c|c|c|c|c|c|}
\hline & Option & $\mathrm{A}$ & B & $\mathrm{C}$ & $\mathrm{D}$ & E & Total answers & $\begin{array}{c}\text { Total questions } \\
\text { without answers }\end{array}$ & Total \\
\hline \multirow{2}{*}{ Task1 } & $\mathrm{f}$ & - & - & - & - & - & 604 & 0 & \multirow{2}{*}{604} \\
\hline & $\%$ & - & - & - & - & - & 100 & 0 & \\
\hline \multirow{2}{*}{ Task2 } & $\mathrm{f}$ & 240 & 12 & 67 & 13 & 206 & 548 & 56 & 604 \\
\hline & $\%$ & 43.8 & 2.2 & 12.2 & 14.2 & 37.6 & 100 & & \\
\hline \multirow{2}{*}{ Task3 } & $\mathrm{f}$ & 238 & 52 & 33 & 135 & 105 & 563 & 41 & 604 \\
\hline & $\%$ & 42.3 & 9.2 & 5.9 & 24 & 18.7 & 100 & & \\
\hline \multirow{2}{*}{ Task4 } & $\mathrm{f}$ & 32 & 88 & 35 & 24 & 344 & 523 & 81 & 604 \\
\hline & $\%$ & 6.1 & 16.8 & 6.7 & 4.6 & 65.8 & 100 & & \\
\hline \multirow{2}{*}{ Task5 } & $\mathrm{f}$ & 125 & 65 & 74 & 56 & 106 & 426 & 178 & 604 \\
\hline & $\%$ & 29.3 & 15.3 & 17.4 & 13.1 & 24.9 & 100 & & \\
\hline \multirow{2}{*}{ Task6 } & $\mathrm{f}$ & 41 & 94 & 23 & 350 & 16 & 524 & 80 & 604 \\
\hline & $\%$ & 7.8 & 17.9 & 4.4 & 66.8 & 13.1 & 100 & & \\
\hline \multirow{2}{*}{ Task7 } & $\mathrm{f}$ & 282 & 52 & 54 & 39 & 67 & 494 & 110 & 604 \\
\hline & $\%$ & 57.1 & 10.5 & 10.9 & 7.9 & 13.6 & 100 & & \\
\hline \multirow{2}{*}{ Task8 } & $\mathrm{f}$ & 56 & 396 & 76 & 19 & 26 & 513 & 31 & 604 \\
\hline & $\%$ & 9.8 & 69.1 & 13.3 & 3.3 & 4.5 & 100 & & \\
\hline \multirow{2}{*}{ Task9 } & $\mathrm{f}$ & 67 & 358 & 41 & 44 & 21 & 531 & 73 & 604 \\
\hline & $\%$ & 12.6 & 67.4 & 7.7 & 8.3 & 4 & 100 & & \\
\hline
\end{tabular}

Task 1 (The term "derivative"): What does derivative mean to you? Explain it as you can. If possible, give a tangible example of your surroundings.

Table 4 illustrates the correct or incorrect answers of the students to task 1 . In task 1 , we look at what students generally understand the word derivative and we want to express it in simple language. Almost $65 \%$ of the students introduced derivative as the tangent line slope, i.e., they were at the layer of the limit and graphical context in terms of the framework of Zandieh. In addition, $15 \%$ of the students were in the verbal context, i.e. the rate of change (velocity, acceleration, rate, etc.) and function layer, $10 \%$ of the students were in the symbolic context and function layer, and 10\% misunderstood and had instrumental or non-layer understanding. One of the students stated, "In my opinion, derivative means the shift of a difficult theory into an easy one. For example, 
$y=2 x \rightarrow y^{\prime}=2$ and sometimes the opposite occur, but the derivative of difficult formulas are very difficult". Most engineering students introduced derivative based on their perspectives and the field they studied. For example, derivative means "creating changes in a function to achieve some information about it - changing the function into another one for using it in signals. Some conceptual mistakes were observed in the interpretations of students on derivative for example "derivative means $f^{\prime}(x)=\frac{f(x)-f(a)}{x-a}$ or derivative means putting the power of an expression as its coefficient and subtract one from its power. For example, $3 x^{2} \rightarrow 6 x$.

Table 4

An example of the student's answers to task 1

\begin{tabular}{|c|c|c|c|}
\hline Layer-context & Incomplete or incorrect answers & Layer-context & $\begin{array}{c}\text { Correct or relatively correct } \\
\text { answers }\end{array}$ \\
\hline $\begin{array}{l}\text { Instrumental } \\
\text { understanding } \\
\text { symbolic }\end{array}$ & $\begin{array}{l}\text { Reducing the power of the } \\
\text { - introduced function, for example } \\
f(x)=x^{3} \rightarrow f^{\prime}(x)=3 x^{2}\end{array}$ & $\begin{array}{l}\text { Limit- } \\
\text { graphical }\end{array}$ & $\begin{array}{l}\text { Curve slope-line slope-tangent } \\
\text { line slope to the function } \\
\text { curve. }\end{array}$ \\
\hline Ratio-symbolic & $f^{\prime}(x)=\frac{f(x)-f(a)}{x-a}$ & $\begin{array}{l}\text { Function- } \\
\text { physical }\end{array}$ & $\begin{array}{l}\text { Obtaining instantaneous value } \\
\text { of one } x \text { than } y \text {, like the } \\
\text { speed of cat at moment } t \text { on } \\
\text { one route }\end{array}$ \\
\hline
\end{tabular}

Table 5

Example of coding the students' answers to task 1 based on the framework of Zandieh

expression
Function slope
Tangent line slope to curve
or velocity

The coding was performed based on the framework of Zandieh as shown in Figure 1. The arrows in Table 5 show that some students established a connection between two or more contexts of the concept of derivative. Table 5 indicates that the students have reached all three layers of the framework of Zandieh in terms of slope but the layers are very few in the numerical context. In case of the connection between the contexts, slope and symbol had the most connection. 
Task 2 (Relative rate of change): Every second, Ali rides a bicycle $j$ meter and Reza walk on foot, so that $j>s$, how can the distance traveled by Reza and Ali be compared at a given time? (Byerley and Thompson, 2017)

a) Ali will travel $j-s$ meter more than Reza.

c) Ali will travel $j / s$ meter more than Reza.

b) Ali will travel $j . s$ meter more than Reza.

e) Ali will travel $j / s$ equal to Reza.

d) Ali will travel $j . s$ equal Reza.

One of our goals in assessing students' understanding of the derivative is to put one physical position in the task and understanding the relative rate of change. Table 3 shows that 548 subjects answered task 2 while 56 subjects did not answer. Further, 240 subjects (43.8\%) chose option "a" and only 206 subjects (37.6\%) chose option "e" (correct option).

Putting a physical position in the problem and understanding the relative rate with a simple question were the main objectives of this study in evaluating students' understanding of derivative. Only $37.6 \%$ of the students answered correctly. In addition, $43.8 \%$ of the students selected option "a" representing the collective thinking prevailing the multiplicative thinking among them. We normally act like below for comparing two expressions $x_{1}=j t, x_{2}=s t$ : i) $x_{1}-x_{2}=(j-s) t$;ii) $\frac{x_{1}}{x_{2}}=\frac{j}{s}$. If $t=1$, both formulas $\mathrm{i}$ and ii can be used for comparison. However, the parameter time should be eliminated by dividing so that it does not depend on time for a certain time based on the given task and options. Therefore, formula $i i$ is used. However, most of the students attempted to use formula $i$, unaware that this relation can be established for $t=1$, which is the same prevailing thinking among the students.

Table 6

Example of the students' answers to task 2

\begin{tabular}{|c|c|c|c|}
\hline layer & $\begin{array}{l}\text { Incomplete or incorrect } \\
\text { answers }\end{array}$ & layer & Correct or almost correct answers \\
\hline Ratio & $\begin{array}{l}\text { Option } a \text { is correct } \\
\text { because at every second, } \\
\text { Reza moves } s \text { meter } \\
\text { forward while Reza } \\
\text { moves } j \text { meter forward. } \\
\text { Thus, Ali moves } j-s \\
\text { meter forward. } \\
\text { Explanation: } \\
\text { comparison is correct } \\
\text { when we have } t=1 \text {. }\end{array}$ & Function & $\begin{array}{l}\text { Option } e \text { is correct because at any moment, } \\
\text { the distance traveled by Ali } \frac{j}{s} \text { equals the } \\
\text { distance traveled by Reza. }\end{array}$ \\
\hline \multirow[t]{2}{*}{$\begin{array}{l}\text { Instrumental } \\
\text { understanding }\end{array}$} & $\begin{array}{l}\text { Option } a \text { is correct } \\
\text { because the distance they } \\
\text { both traveled is not } \\
\text { related to their velocity } \\
\text { or riding/walking. }\end{array}$ & Function & $\begin{array}{l}\text { Option } e \text { is correct because } \\
v_{1}=j \mathrm{~m} / \mathrm{s} \rightarrow x_{1}=v_{1} t \\
v_{2}=s \mathrm{~m} / \mathrm{s} \rightarrow x_{2}=v_{2} t\end{array}$ \\
\hline & $\begin{array}{l}\text { Explanation: At a specific } \\
\text { time, distances can vary } \\
\text { based on velocity. }\end{array}$ & & $\begin{array}{l}\Rightarrow \frac{x_{1}}{x_{2}}=\frac{v_{1}}{v_{2}} \rightarrow x_{1}=\frac{j}{s} x_{2} \\
(\mathrm{~m} / \mathrm{s} \text { means that meter per second) }\end{array}$ \\
\hline
\end{tabular}


As can be observed in Table 3, the maximum number of answers is related to options $a$ and e, although $a$ is more and cannot be a good sign. The students who chose option $a$ argued that "option $a$ is correct because Ali, who traveled a longer distance is subtracted from the distance travelled by Reza to obtain the distance Ali has traveled more." Or "option $a$ is correct because when we want to calculate the distance between two points, we use subtraction." Most of the students who answered incorrectly were at the layer of ratio or instrumental understanding of derivative in the verbal context (see in table 6).

Task 3 (Calculating the graph slope without uniting (approximate)): What is the approximate slope of the following line? (Byerley \& Thompson, 2017; with modification) a) A number between 2 and 3 b) A number less than 2

c) A number more than 3

d) It cannot be calculated approximately

e) $m=\frac{y_{2}-y_{1}}{x_{2}-x_{1}}=\tan 60^{\circ}$

Give a reason for your choice.

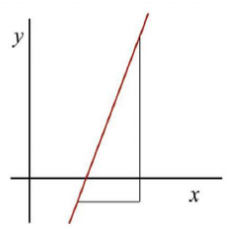

The aim of task 3 is to investigate the numerical context of Zandieh framework with a graph without unit. Table 3 displays that $42.3 \%$ of the students chose the correct answer of option $a$. Many of the students could not calculate the slope approximately and were looking for a specific angle or uniting of axes and constantly stated if the question had any problem. As shown in Table 7, most of the students were placed at the layer of ratio or the instrumental understanding of the framework in the numerical context of calculating the slope.

Table 7

The example of the students' answers to task 3

\begin{tabular}{ll}
\hline layer & Incomplete or incorrect answers \\
\hline Ratio & Option $b$ is correct because \\
& $\tan 45^{\circ}=1$ and it is obviously \\
& a degree more than 45 and less \\
& than 90.
\end{tabular}
Layer Function Correct or almost correct answers

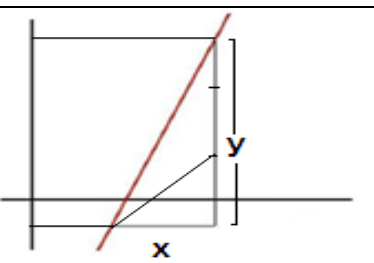

Option $a$ is correct because $2 x<y<3 x$

Instrumental Option $d$ is correct because a Limit Option $a$ is correct because if we understanding number will be obtained draw the lines $y=x$ and $y=2 x$, depending on the values $x_{1}, x_{2}$, the line slope will be more than 2 . $y_{1}, y_{2}$, and $m=\frac{y_{2}-y_{1}}{x_{2}-x_{1}}$.
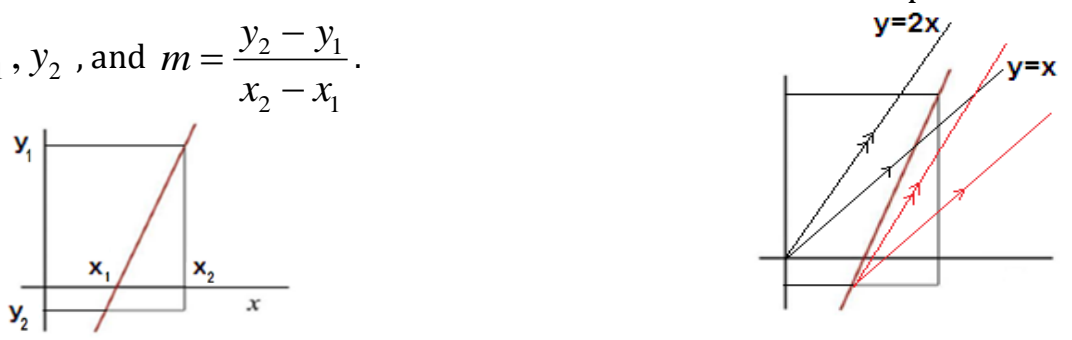

Task 3 is used to find the relative size of the changes $y$ relative to the changes $x$. The context of the problem is calculating the numerical value of the slope. Students should calculate and approximate $\frac{\Delta y}{\Delta x}$ in terms of the unit $\Delta x$.

Table 7 displays a variety of students' correct and incorrect answers. As shown, $42.3 \%$ of the students answered correctly and obtained an approximate number of 2.5 . 
Multiple strategies and conceptual errors in this problem were among its considerable points. Table 3 indicates that $18.7 \%$ of the students obtained the slope from $m=\frac{y_{2}-y_{1}}{x_{2}-x_{1}}=\tan 60^{\circ}$ representing that they had an understanding of slope.

Task 4 (Finding the function criterion): The values in the following table are true for $y=f(x)$ (Pino-Fan et al., 2018; with modification)

\begin{tabular}{ll}
\hline$x$ & $f^{\prime}(x)$ \\
\hline 0 & 0 \\
1.0 & 2 \\
1.5 & 3 \\
2.0 & 4 \\
2.5 & 5 \\
\hline
\end{tabular}

i) Find a relation for $f(x)$ ii) How many different answers can be found for $f(x)$ ?
a) 0
b) 1
c) 2
d) 4
e) Infinite

The aim of this task is how students will get from the numerical values of the derivative function to the antiderivative function. Table 3 shows that $65.8 \%$ of the students chose the correct answer.

Table 8

An example of the students' answers to task 4 (the first and second parts)

\begin{tabular}{llll}
\hline layer & Incomplete or incorrect answers & Layer & Correct or almost correct answers \\
\hline Ratio & Function & A: $f(x)=x^{2}$ \\
& A: $f(x)=\frac{x^{4}}{2}$ & B: $f(x)=x^{2}+c$ infinite answers are \\
& B: 1 & obtained by changing the $c$ value.
\end{tabular}

Explanation: $f^{\prime}(x)=2 x^{3}$ was considered.

Instrumental understanding

$\mathrm{A} f(x)=2 x: \mathrm{B}: 0$

Explanation: $f^{\prime}(x)$ was confused with $f(x)$.
Function

\begin{tabular}{|c|c|c|}
\hline \multicolumn{3}{|c|}{ With the help of table and modeling } \\
\hline$x$ & $f^{\prime}(x)$ & \\
\hline 0 & $2(0)=0$ & \\
\hline 1.0 & $2(1)=2$ & On the other hand, \\
\hline 1.5 & $2(1.5)=3$ & $f(x)=x^{n} \quad$ equals \\
\hline 2 & $2(2)=4$ & $f^{\prime}(x)=n x^{n-1}$ \\
\hline : & : & thus \\
\hline & & $f(x)=x^{2}$ \\
\hline$x$ & $2 x$ & \\
\hline
\end{tabular}

The required knowledge for solving task 4 is integral and calculus theorems. Table 8 categorizes the correct and incorrect answers to task 4. Multiple solutions and conceptual errors are observed in this task. Based on the results, 88 of the students reached number 1 while answering Section (ii) indicating that they had no appropriate understanding of the concept of initial function, unlike they called derivative contrary to integral in the derivative phrase section. The percentage of the students being at the layer of function and limit is more than $50 \%$.

Task 5 (The numerical representation of average rate of change): A ball is thrown into the air from a bridge with 11-meter height. $f(t)$ represents the distance between the ball and 
the ground at time $t$. Some values of $f(t)$ are shown in the following table (Pino-Fan et al., 2018).

\begin{tabular}{cccccccc}
\hline $\begin{array}{c}\text { (Second) } \\
t(s)\end{array}$ & 0 & 0.1 & 0.2 & 0.3 & 0.4 & 0.5 & 0.6 \\
\hline $\begin{array}{c}\text { (Meter) } \\
f(t)(m)\end{array}$ & 11 & 12.4 & 13.8 & 15.1 & 16.3 & 17.4 & 18.4 \\
\hline
\end{tabular}

Based on the table, how much is the approximate velocity of the ball per $t=0.4$ second? Justify your answer.
a) $11.5 \mathrm{~m} / \mathrm{s}$
b) $1.23 \mathrm{~m} / \mathrm{s}$
c) $14.91 \mathrm{~m} / \mathrm{s}$
d) $16.3 \mathrm{~m} / \mathrm{s}$
e) something else

The purpose of this task is to calculate the derivative at a point using a table of numerical values. Table 3 indicates that only $29.3 \%$ of the students answered correctly while $70.7 \%$ answered incorrectly.

\section{Table 9}

An example of the students' answers to task 5

\begin{tabular}{|c|c|c|c|}
\hline Layer & Incomplete or incorrect answers & layer & Correct or almost correct answers \\
\hline Ratio & $\begin{array}{l}\text { Option } e \text { is correct because } \\
x=16.3-11=5.3 \\
v=\frac{x}{t}=\frac{5.3}{0.4}=13.25\end{array}$ & Limit & 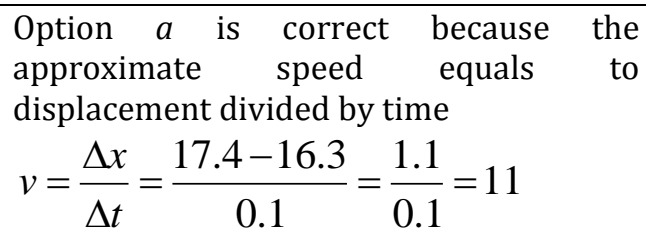 \\
\hline Ratio & $\begin{array}{l}\text { Option } e \text { is correct because } \\
x=16.3-11=5.3 \\
v=\frac{x}{t}=\frac{5.3}{0.4}=14.91\end{array}$ & Function & $\begin{array}{l}\text { Option } a \text { is correct because } \\
v_{1}=\frac{\Delta x_{1}}{\Delta t_{1}}=\frac{17.4-15.1}{0.5-0.4}=11.5 \\
v_{2}=\frac{\Delta x_{2}}{\Delta t_{2}}=\frac{18.4-13.8}{0.6-0.2}=11.5\end{array}$ \\
\hline
\end{tabular}

Most of the students were looking for physics formulas to answer this question and they seemed highly confused (Table 9). Approximate velocity using the table looked difficult and the connection between the table data and the secant lines on the graph could not be established. The percentage of the students who answered the question incorrectly and were at the numerical context in layer of ratio or instrumental understanding is more than $70 \%$.

Task 5 (Deriving the function with several variables): The gravitational force of the earth $F$, which depends on the distance between the object and the center of the earth $(r)$, is given by the formula $F=\frac{G m M}{r^{2}}(M=$ the mass of the earth, $m=$ the mass of the object and $G$ =gravitational constant). Which one is $\frac{d F}{d r}$ or $F^{\prime}(r)$ and what does this answer tell you? (Jones, 2017)
a) $F^{\prime}(r)=\frac{\left(G m M^{\prime}\right)\left(r^{2}\right)-(G m M)(2 r)}{\left(r^{2}\right)}$
b) $F^{\prime}(r)=\frac{m\left(r^{2}\right)-2 r(G m M)}{r^{4}}$
c) $F^{\prime}(r)=\frac{G\left(m^{\prime} M^{\prime}\right)\left(r^{2}\right)-2 r(G m M)}{r^{3}}$
d) $F^{\prime}(r)=\frac{-2 G m M}{r^{3}}$
e) $F^{\prime}(r)=\frac{-(G m M)}{r^{2}}$ 
The purpose of this task is to calculate the derivative for a particular variable from among several variables. As shown in Table 3,66.8\% of the students gave the correct answer. Since this task has a procedural aspect, a higher percentage of the students was expected to answer correctly. The percentage of the students in the function layer is more than $60 \%$ (see table 10 ).

\section{Table 10}

An example of the students' answers to task 6

\begin{tabular}{|c|c|c|c|}
\hline layer & Incomplete or incorrect answers & layer & Correct or almost correct answers \\
\hline Ratio & $F^{\prime}(r)=\frac{-(G m M)}{r^{2}}$ & Function & $\begin{array}{l}\text { option } d \text { is correct and situations that the } \\
\text { changes of force in terms of the changes of } \\
\text { distance is related to the parameters } m, M, G\end{array}$ \\
\hline ratio & $F^{\prime}(r)=\frac{G\left(m^{\prime} M^{\prime}\right)\left(r^{2}\right)-2 r(G m M)}{r^{4}}$ & Limit & $\begin{array}{l}\text { and the reverse of the distance cube. } \\
\text { option } d \text { is correct and shows how the force of } \\
\text { gravity applied to the object changes. }\end{array}$ \\
\hline ratio & $F^{\prime}(r)=\frac{m\left(r^{2}\right)-2 r(G m M)}{r^{4}}$ & Function & $F^{\prime}(r)=\frac{-2 r G m M}{r^{4}}$ \\
\hline
\end{tabular}

Task 7 (The function of tangent line): For function $f$ we have $f^{\prime}(4)=1.5$ in the following Figure. What is the point $B$ based on the width of the point? (Hughes-Hallett et al., 2017)
a) $y_{B}=25.3$
b) $y_{B}=37.3$
c) $y_{B}=25.1$
d) $y_{B}=25.2$

e) it can not be calculated

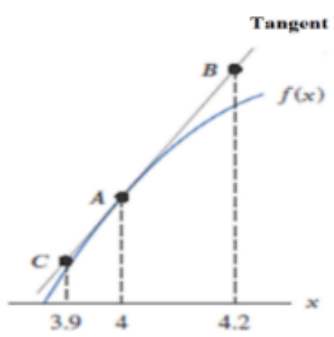

The purpose of this task is to identify and apply the tangent line at a specific point. Table 3 displays that $57.1 \%$ of the students answered correctly to this task 7 . Multiple solutions and misconceptions observed in table 11.

Table 11

An example of the students' answers to task 7

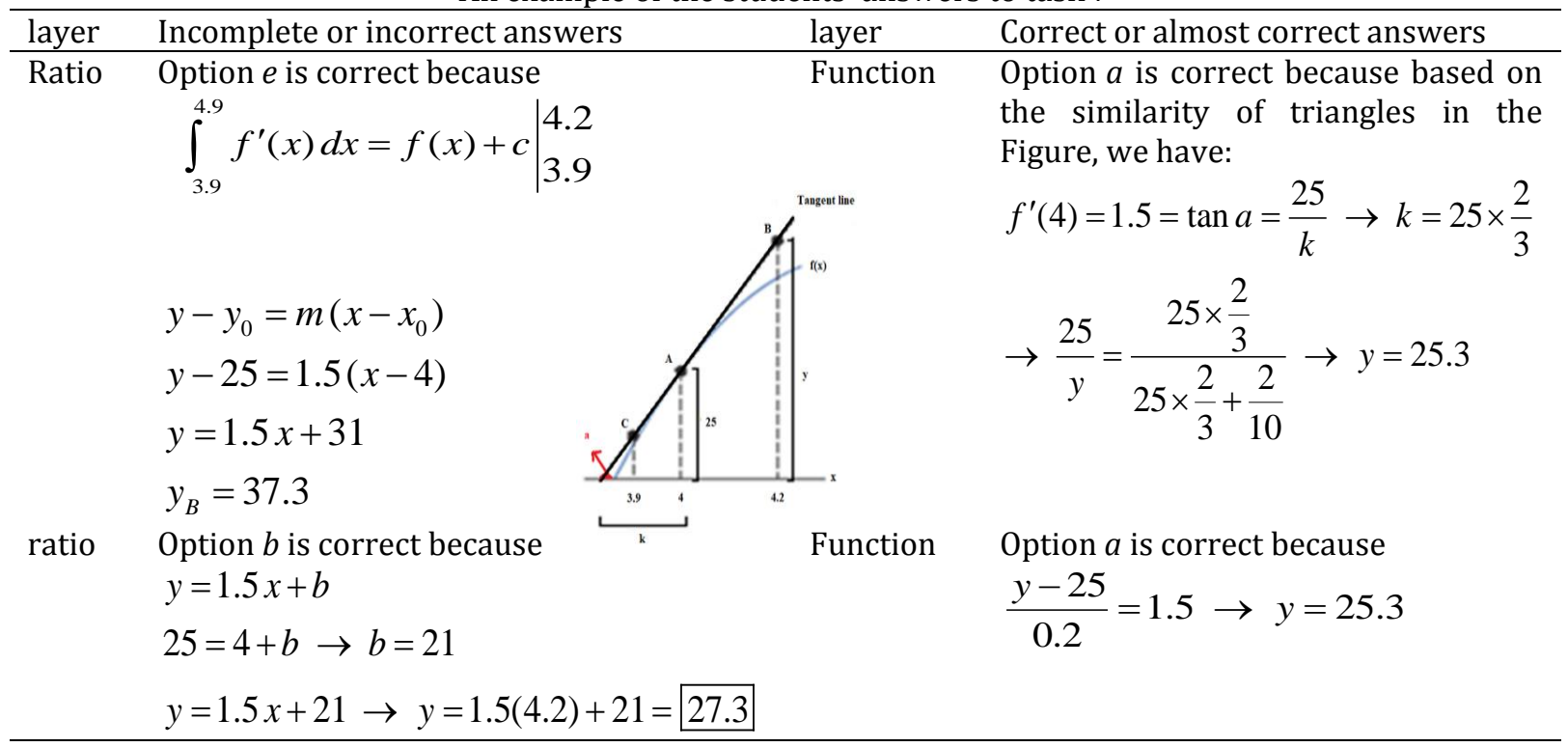


Table 3 indicates that more than $50 \%$ of the students were in the function layer in the slope context.

Task 8 (Understanding the slope of points and comparing them): Consider the points $A, B, C, D, E, F$ on the following curve. Which expression is correct about the slope of the curve at these points? (Hughes-Hallett et al., 2017)

a) $m_{B}=m_{E}<m_{D}<m_{A}<m_{F}<m_{C}$

b) $m_{F}<m_{C}<m_{E}=m_{B}<m_{D}<m_{A}$

c) $m_{E}<m_{B}<m_{C}<m_{D}<m_{A}<m_{F}$

d) $m_{A}<m_{F}<m_{D}<m_{C}<m_{B}<m_{E}$

e) $m_{F}<m_{A}<m_{D}<m_{C}<m_{B}<m_{E}$

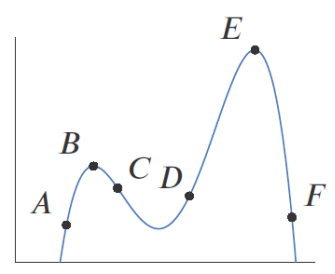

The purpose of this task is to assess students' ability to compare slopes on graph. As Table 3 shows, $69.1 \%$ of the students gave the correct answer to this task. As can be seen in Table 12, students used tangent lines as a strategy in solving task 8.

Table 12

An example of the students' answers to task 8

\begin{tabular}{llll}
\hline layer & Incomplete or incorrect answers & layer & Correct or almost correct answers \\
\hline Ratio & Option $\mathrm{d}$ is correct because & Function & Option b is correct because \\
ratio & &
\end{tabular}

Table 12 indicates the prevailing strategy of the students in doing task 8 to which $69.1 \%$ of the students gave the correct answer. More than $80 \%$ of the students were in the layer of function or limit in the slope context.

Task 9 (Magnification of graph and derivative): The graph of the two functions $f$ and $g$, as well as their magnification is drawn in the intervals $[0,1]$ and $[0.4,0.6]$. Which one of the functions is differentiable at point 0.5 ? Explain (Giraldo \& Carvalho, 2003).

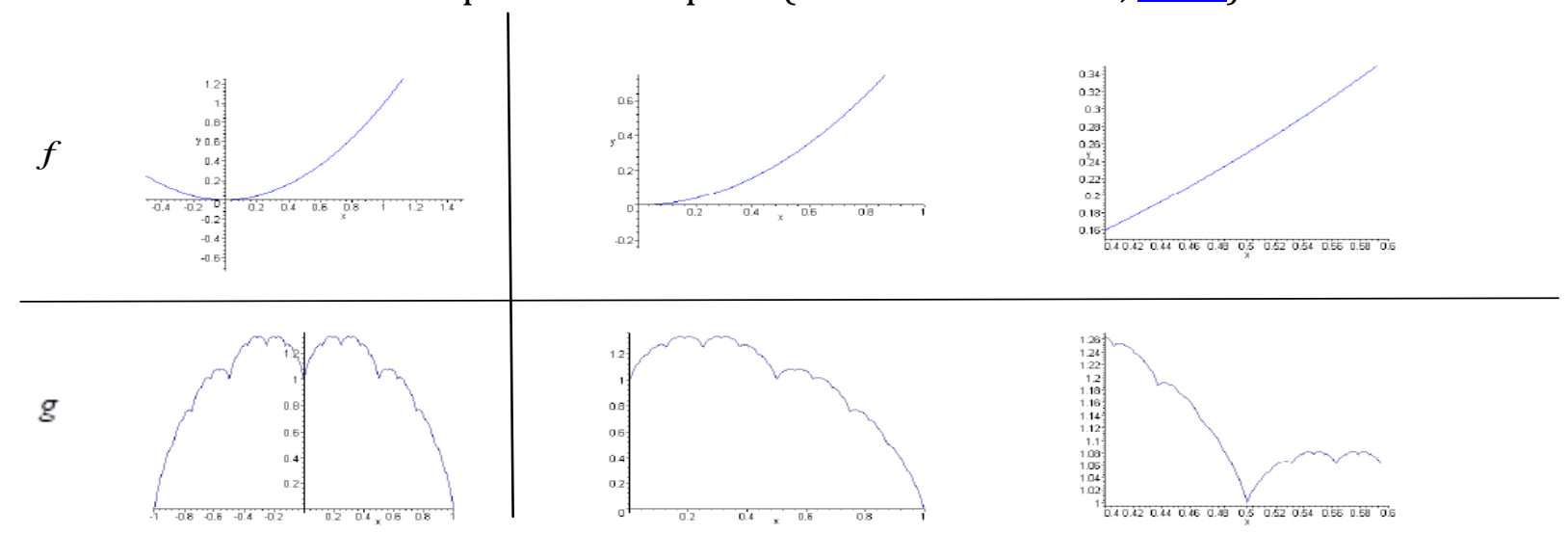



a) Both functions $f, g$
b) just function $f$
c) just function $g$
d) none
e) information is not adequate.

The purpose of this task is to identify the linearization aspect and the derivative approximation at a point on the graph. As shown in Table 3,67.4\% of the students gave the correct answer to this task.

Table 13

An example of the students' answers to task 9

\begin{tabular}{|c|c|c|c|}
\hline layer & Incomplete or incorrect answers & layer & $\begin{array}{llll}\begin{array}{l}\text { Correct } \\
\text { answers }\end{array} & \text { or almost } & \text { correct } \\
\end{array}$ \\
\hline ratio & $\begin{array}{l}\text { Option } e \text { is correct because it may be } \\
\text { differentiable with more magnification } \\
\text { at all points. }\end{array}$ & Function & $\begin{array}{l}\text { Option } b \text { is correct because it } \\
\text { looks continuous and also the left } \\
\text { and right limits of the function } \\
\text { are equal. }\end{array}$ \\
\hline limit & $\begin{array}{l}\text { Option } e \text { is correct because if the } \\
\text { function } g \text { at the adjacency } 0.5 \text { has } \\
\text { numerous fluctuations, no derivative } \\
\text { can be performed at } 0.5 \text {, however the } \\
\text { function } f \text { looks differentiable at } 0.5 \text {. }\end{array}$ & limit & $\begin{array}{l}\text { Option } b \text { is correct because the } \\
\text { function } g \text { has no left or right } \\
\text { derivatives around the point. }\end{array}$ \\
\hline
\end{tabular}

Table 13 indicates more than $60 \%$ of the students were in the layer of limit and function in terms of graphical analysis.

Description of test statistics

In this study, 604 students were selected as the sample in a researcher-made test. Here is the description of statistics in general and the results of these tests:

The students' distribution in terms of gender

Table 14 shows the distribution of the participants in terms of gender.

Table 14

The students' distribution in terms of gender

\begin{tabular}{llll}
\hline & Absolute frequency & Relative frequency percentage & Cumulative frequency percentage \\
\hline Female & 342 & 57.0 & 57.0 \\
Male & 262 & 43.0 & 100.0 \\
Total & 604 & 100.0 & \\
\hline
\end{tabular}

As shown in Table 14, the total number of subjects is 604, among whom 342 are female and 262 are male. The test questions with the number of answers to each option and their analysis are presented separately.

\section{Descriptive statistics}

The descriptive statistics of the answers given by the students in Tehran universities to each task are specified in Table 15. As shown, the following results were obtained as follows. The maximum number of the students answering to task 8 is 573 and the minimum number of the students answering to task 5 is 426 . A number of 178 students did not answer to task 5.The median of task 2 and task 5 is 2 points and the median of task 3 is 3 points. The maximum frequency of task 2 is 2 points. The maximum mean of the scores of students' understanding of derivative in task 8 is 3.40 while the minimum mean of the scores of students' understanding of derivative in task 5 is 2.11 . The maximum score for each task is 4 . The maximum variance of scores occurred in task 3 (2.67) while the minimum score variance occurred in task 6 (1.03). The maximum total score is related to 
task 8 (1950 points), task 6 (1787 points) and task 9 (1762 points) while the lowest total score is in task 5 was 899 points.

Table 15

Descriptive statistics of the answers given by the students in Tehran universities to each task

\begin{tabular}{lllllllll}
\hline & Task 2 & Task 3 & Task 4 & Task 5 & Task 6 & Task 7 & Task 8 & Task 9 \\
\hline Number of valid data & 548 & 563 & 523 & 426 & 524 & 494 & 573 & 531 \\
Number of lost data & 56 & 41 & 81 & 178 & 80 & 110 & 31 & 73 \\
Mean & 2.79 & 2.33 & 3.07 & 2.11 & 3.41 & 2.84 & 3.40 & 3.32 \\
Standard error of mean & .046 & .069 & .061 & .076 & .044 & .068 & .044 & .050 \\
Median & 2.00 & 3.00 & 4.00 & 2.00 & 4.00 & 4.00 & 4.00 & 4.00 \\
Mode & 2 & 4 & 4 & 4 & 4 & 4 & 4 & 4 \\
Standard deviation & 1.066 & 1.633 & 1.395 & 1.564 & 1.015 & 1.517 & 1.053 & 1.150 \\
Variance & 1.136 & 2.668 & 1.947 & 2.447 & 1.030 & 2.302 & 1.108 & 1.323 \\
Rate of changes & 4 & 4 & 4 & 4 & 4 & 4 & 4 & 4 \\
Minimum & 0 & 0 & 0 & 0 & 0 & 0 & 0 & 0 \\
Maximum & 4 & 4 & 4 & 4 & 4 & 4 & 4 & 4 \\
Total scores & 1528 & 1309 & 1606 & 899 & 1787 & 1405 & 1950 & 1762 \\
\hline
\end{tabular}

\section{Answer the main questions}

First main question: Table 16 indicates the mean comparison of engineering and basic sciences students' relational understanding of derivative based on independent t-test.

\section{Table 16}

T-test for comparing the two groups of engineering and basic sciences in terms of the score of the students' understanding the concept of derivative

\begin{tabular}{lllllc}
\hline Group & Mean & Standard deviation & t & df & $p$ \\
\hline Engineering $(\mathrm{N}=279)$ & 21.06 & 5.89 & -2.95 & 602 & $<0.05$ \\
Basic sciences $(\mathrm{N}=325)$ & 19.60 & 6.20 & & & \\
\hline
\end{tabular}

The results of Table 16 indicate null hypothesis is rejected and a significant difference between the mean of the two groups of engineering and basic sciences in their understanding of the concept of derivative. The mean score of engineering students is 21.06 and the mean score of basic sciences students is 19.06 in terms of understanding the concept of derivative. The basic science students were mostly studying in mathematics or computer science and they had logically no difficulty in the basic concepts of derivative (Figure 2).

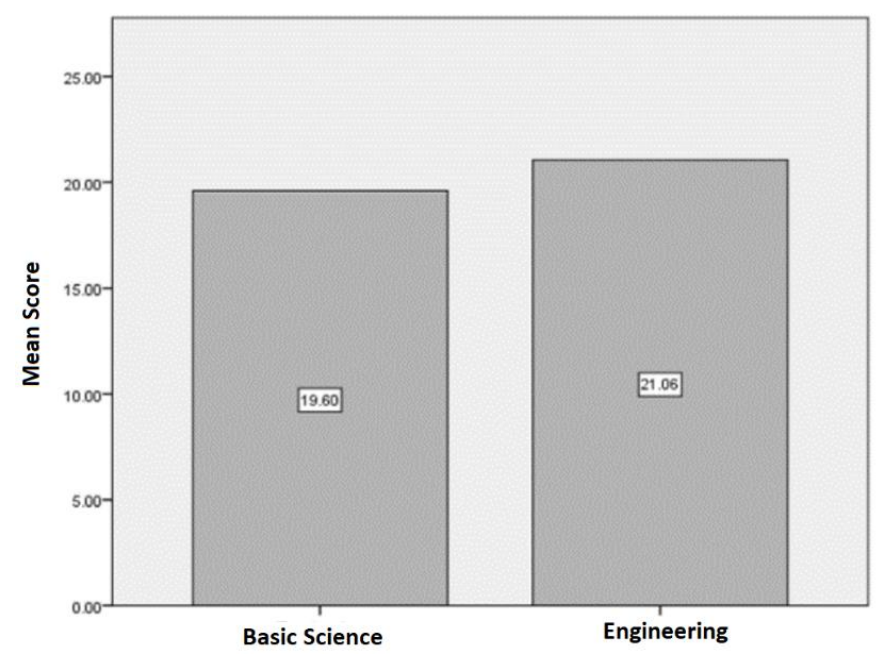

Figure 2. Bar graph of the mean comparison of engineering and basic sciences students' score in in their understanding of derivative 
Based on the independent t-test (Table 16), there is a significant difference between the mean scores of engineering and basic science students' understanding of the concept of derivative.

The maximum mean score of students 'understanding of derivative is related to task 8 (3.40) while the minimum mean score of students' understanding of derivative is in task 5 (2.11). The maximum score for each task is 4 . The maximum score variance occurred in task 3 (2.67), while the minimum score variance occurred in task 6 (1.03). Task 8 aims at comparing the slopes from the graph and task 5 aims at calculating the average change rate numerically. Students were confused in task 5 and had no appropriate understanding of calculating the average rate of change at a specific moment. Physical formulas or mathematical expressions were used incorrectly. The minimum number of students answered to this question and the mean of 2.11 out of 4 indicates the difficulty of this task for students. Although using the meaning of additive and increase for the slope and rate of change at certain situations results, this meaning can lead to invalid models of physical situations. Answering to the relative rate shows an increase in the rate of change. Most of the students $(43.8 \%)$ chose the wrong option of a. The maximum total scores were obtained by the students in task 8 (1950 points), task 6 (1787 points) and task 9 (1762 points) while the minimum total score was in task 5 with 899 points.

Second main question: The results of Table 17 indicate that the minimum percentages of the students were in the layers of ratio, limit, and function is related to in tasks 5 and 2 . In addition, the percentage of the basic science students covering the derivative layers is lower than the engineering students.

Table 17

Results of the percentage of answers by engineering and basic sciences students to each question based on the expanded framework of Zandieh (2000)

\begin{tabular}{lllll}
\hline Field & Task & Ratio (\%) & Limit (\%) & Function (\%) \\
\hline Engineering & T1 & 90 & 60 & 56 \\
Basic sciences & & 88 & 57 & 51 \\
Engineering & T2 & 50 & 49.7 & 39.3 \\
Basic sciences & & 49 & 47 & 37.5 \\
Engineering & T3 & 87.3 & 36.7 & 53.3 \\
Basic sciences & & 87.5 & 47.5 & 55 \\
Engineering & T4 & 87.7 & 43.3 & 63.3 \\
Basic sciences & & 97.5 & 55 & 42.5 \\
Engineering & T5 & 49.7 & 43.4 & 36.7 \\
Basic sciences & & 35.5 & 31.5 & 25 \\
Engineering & T6 & 100 & 63.7 & 59.7 \\
Basic sciences & & 100 & 62 & 49.5 \\
Engineering & T7 & 87.3 & 40 & 46.7 \\
Basic sciences & & 87.5 & 35 & 62.5 \\
Engineering & T8 & 100 & 61 & 60 \\
Basic sciences & & 100 & 67.5 & 62 \\
Engineering & T9 & 100 & 93.1 & 51.7 \\
Basic sciences & & 100 & 85 & 47.5 \\
\hline
\end{tabular}

In general, the students understood the layers of slope better than the other layers. Table 17 indicates the distribution of the frequency percentage of limit, function and derivative based on the framework of Zandieh for engineering and basic sciences students. The results indicated that the percentage of the students in the function layers is very low. The percentage of the engineering students is higher than the basic sciences students 
covering the layers of ratio, limit and function. In tasks 3, 7, and 8, the basic sciences students allocated higher percentages of layer than the engineering students.

Third main question: Table 18 indicates the comparison of the percentage of answers by engineering and basic sciences students to each question.

Table 18

Comparison of the percentage of answers by engineering and basic sciences students to the questions

\begin{tabular}{|c|c|c|c|}
\hline Task & Subject & $\begin{array}{l}\text { Percentage of } \\
\text { correct answer to } \\
\text { the problem (Basic } \\
\text { sciences) }\end{array}$ & $\begin{array}{l}\text { Percentage of correct } \\
\text { answer to the } \\
\text { problem } \\
\text { (Engineering) }\end{array}$ \\
\hline T1 & Derivative expression & 70 & 85 \\
\hline $\mathrm{T} 2$ & Relative rate of change & 37.5 & 39.3 \\
\hline T3 & Slope of a graph without uniting & 64 & 63.3 \\
\hline $\mathrm{T} 4$ & Function criterion & 42.5 & 63.3 \\
\hline T5 & Calculating velocity numerically & 25 & 36.7 \\
\hline T6 & Function derivative & 45 & 66.7 \\
\hline T7 & The use of tangent line & 49.5 & 46.7 \\
\hline T8 & $\begin{array}{l}\text { Understanding the slope of points and } \\
\text { comparing them }\end{array}$ & 65 & 60 \\
\hline T9 & Magnifying the graph and derivative & 37.5 & 51.7 \\
\hline
\end{tabular}

Based on the results in Table 18, in tasks 3, 7, and 8 (the slope of a graph without uniting and the use of tangent line and understanding the slope of points and comparing them), the basic science students performed better than the engineering students, and vice versa in other cases. In general, the engineering students performed better in graphical, verbal, numerical, and physical contexts. In addition, the frequency percentage of the engineering and basic sciences students in different contexts is shown in Table 21. The results indicate that the students failed at performing appropriately in the numerical and physical contexts. The basic science students had more correct answers than the engineering students in tasks 3, 7, and 8 while the engineering students answered better in other tasks.

\section{Discussion}

The present study aimed to investigate the undergraduate engineering and basic sciences students' understanding of the concept of derivative based the framework of Zandieh ( $\underline{2000})$ in Tehran universities. The literature review on derivative documents that many students and some teachers have difficulties connecting multiple representations and partial meanings associated with the derivative (i.e. Borji et al., 2018; Pino-Fan et al., 2018; Fuentealba, Badillo \& Sánchez-Matamoros, 2019; Feudel \& Biehler, 2021; RodríguezNieto, Rodríguez-Vásquez \& Moll, 2020 ; Biza, 2021). The basic science students performed meaningfully better than the engineering students in terms of understanding slope (tasks 3,7 , and 8). The results are consistent with those of Bingolbali et al. (2007), Maull and Berry ( $\underline{2000})$, and Jaafar and Lin (2017). Although the mean scores of the two groups of engineering and basic sciences had no much difference, the engineering students performed better than the basic sciences students in the layers of ratio, limit and function and graphical, physical, symbolic and numerical contexts.

In general, the students' understanding of the concept of derivative was at a weak level. The students understood the concept of slope better than other concepts, although the performance of the basic sciences students in the context of slope was better than the performance of the engineering students. The results are in line with those of Zandieh (2000) and Byerley and Thompson (2017). 
The students performed the weakest performance in the rate of change. In particular, calculating the average rate of change numerically allocated the minimum mean score being answered by the lowest number of students. A kind of complexity occurred in their thoughts and they referred to physical formulas to achieve results, but they chose the wrong approach. The studies by Byerley and Thomson (2017) and Mirin (2018) also confirm this finding. Although the additive meaning for slope and rate resulted in certain states, this meaning can lead to invalid models of physical situations. Answering the relative rate of change shows an increase in the rate of change. This issue was first discussed by Byerley and Thompson (2017) and Weber et al. (2012) and Auxtero and Callaman ( $\underline{2020})$. The same results were obtained in this study and most of the students selected the wrong option $a$. In general, the engineering students performed better in the context of the rate of change than the basic sciences students. Regarding the second question, undergraduate students passed more than $50 \%$ of the ratio layer in all tasks expect tasks 2 and 5 . In tasks 1, 6, 8, and 9, more than half of the students covered the limit layer, and vice versa in other tasks. In tasks 2 and 5, less than half of the students were in the function layer, and vice versa in other tasks.

The basic sciences students in tasks 3, 7, and 8 performed better in all levels of ratio, limit, and function (Except for the limit layer of task 7) compared to the basic sciences students. In other words, the basic sciences students understood the slope of tangent line better than the engineering students. In case of other tasks, the engineering students performed better than the basic sciences students in the layers, i.e., in the concepts of the rate of change and intuitive understanding of graph. The results are consistent with those of Bingolbali et al. (2007) and Maull and Berry (2000) and Carli et al. (2020). Finally, in tasks 3, 7, and 8 (the slope of a graph without uniting and the use of tangent line and understanding the slope of points and comparing them), the basic science students performed better than the engineering students, and vice versa in other cases. In general, the engineering students performed better in graphical, verbal, numerical, and physical contexts. In the intuitive part of derivative and magnification of graph, the students failed at performing well which requires to be speculated. The results are in line with the studies

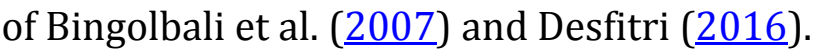

\section{Conclusion}

Based on the results and discussion, it can be concluded that students have no appropriate understanding of the basic concepts of derivatives in numerical, physical, verbal, and graphical contexts. In addition, the relative frequency percentage of engineering students and their mean score of understanding the concept of derivative was significantly higher than that of basic sciences students being in the layers of ratio, limit, and function. Basic sciences students performed meaningfully were better in understanding the tangent line slope compared to engineering students, while engineering students performed meaningfully were better than basic sciences students in the rate of change. In mathematics, derivative has different meanings such as slope, difference quotient limit, rate of change, velocity, acceleration, etc. Some meanings are typically considered more in the undergraduate curricula of different fields for example in engineering, the rate of change is considered more while tangent line slope is regarded more in basic sciences. Inconsistency between the interpretations of slope in mathematics classes and the interpretations of the rate of change in engineering classes may cause some problems for students. Thus, the concepts of slope and rate of change should be considered simultaneously in the curriculum. The students' instrumental understanding of the concept of derivative in their argument was evident in this study; they knew the derivative 
formulas but could not express their meanings. Even the students who passed the differential equations had weak arguments for interpreting the concepts of derivative. Perhaps, too much attention to the instrumental understanding of derivative led to these results. The students could not establish relationships between different representations of derivative or had poor relationships. This means that they had a poor conceptual understanding. This issue can be considered in teaching derivative.

The students' instrumental understanding of the concept of derivative in their argument was evident in this study; they knew the derivative formulas but could not express their meanings. Even the students who passed the differential equations had weak arguments for interpreting the concepts of derivative. Perhaps, too much attention to the instrumental understanding of derivative led to these results. The students could not establish relationships between different representations of derivative and had a poor conceptual understanding of the derivative. This issue could be considered in teaching derivative. Exploring the concept of derivative with other frameworks is also suggested for researchers.

\section{Acknowledgment}

This study is part of the dissertation at Shahid Rajaee Teacher Training University.

\section{Bibliography}

Abd Hamid, H., Idris, N., \& Tapsir, R. (2019). Students' Use of Graphs in Understanding the Concepts of Derivative. Southeast Asian Mathematics Education Journal, 9(1) . https://doi.org/10.46517/seamej.v9i1.69

Ärlebäck, J. B., Doerr, H. M., \& O’Neil, A. H. (2013). A modeling perspective of interpreting rates of change in context. Mathematical Thinking and Learning, 15,314-336. https://doi.org/10.1080/10986065.2013.834405

Asiala, M., Cottrill, J., Dubinsky, E., Schwingendorf, K. (1997). The development of Students' Graphical Understanding of the Derivative, Journal of Mathematical Behavior, 16 (4), 399-431. https://doi.org/10.1016/S0732-3123(97)90015-8

Auxtero, L. C., \& Callaman, R. A. (2020). Rubric as a learning tool in teaching application of derivatives in basic calculus. JRAMathEdu Journal of Research and Advances in Mathematics Education), 6(1), 46-58. https://doi.org/10.23917/jramathedu.v6i1.11449

Baker, B., Cooley, L., \& Trigueros, M. (2000). A calculus graphing schema. Journal for Research in Mathematics Education, 31, 557-578.

Berry, J. S., \& Nyman, M. A. (2003). Promoting students' graphical understanding of the calculus. The Journal of Mathematical Behavior,22(4), 479-495. https://doi.org/10.1016/i.jmathb.2003.09.006.

Bingolbali, E., Monaghan, J., \& Roper, T. (2007). Engineering students' conceptions of the derivative and some implications for their mathematical education. International Journal of Mathematical Education in Science and Technology, 38(6), 763-777. https://doi.org/10.1080/00207390701453579

Biza, I. (2021). The discursive footprint of learning across mathematical domains: The case of the tangent line. The Journal of Mathematical Behavior, 62, 100870. https://doi.org/10.1016/j.jmathb.2021.100870

Borji, V., Alamolhodaei, H., \& Radmehr, F. (2018). Application of the APOS-ACE theory to improve students' graphical understanding of derivative. EURASIA Journal of 
Mathematics, Science and Technology Education, 14(7), 2947-2967. https://doi.org/10.29333/ejmste/91451

Byerley, C., \& Thompson, P. W. (2017). Secondary mathematics teachers' meanings for measure, slope, and rate of change. The Journal of Mathematical Behavior, 48, 168193. https://doi.org/10.1016/i.jmathb.2017.09.003

Carli, M., Lippiello, S., Pantano, O., Perona, M., \& Tormen, G. (2020). Testing students ability to use derivatives, integrals, and vectors in a purely mathematical context and in a physical context. Physical Review Physics Education Research, 16(1), 010111. https://doi.org/10.1103/PhysRevPhysEducRes.16.010111

Carlson, M., Jacobs, S., Coe, E., Larsen, S., \& Hsu, E. (2002). Applying covariational reasoning while modeling dynamic events: A framework and a study. Journal for research in mathematics education, 33(5), 352-378. https://doi.org/10.2307/4149958

Confrey, J., \& Smith, E. (1994). Exponential functions, rates of change, and the multiplicative unit. Educational Studies in Mathematics, 26, 135-164. https://doi.org/10.1007/97894-017-2057-1 2

Cuoco, A. A., \& Curcio, F. R. (2001). The roles of representation in school mathematics. Reston, VA: National council of teachers of mathematics.

Desfitri, R. (2016). In-service teachers' understanding on the concept of limits and derivatives and the way they deliver the concepts to their high school students. In Journal of Physics: Conference Series (Vol. 693, No. 1, p. 012016). IOP Publishing. https://doi.org/10.1088/1742-6596/693/1/012016

English L. D. (2008). Setting an agenda for international research in mathematics education. In Handbook of International Research in Mathematics Education Second Edition, 3-19.

Feudel, F. (2019). Die Ableitung in der Mathematik für Wirtschaftswissenschaftler. Wiesbaden: Springer.

Feudel, F., \& Biehler, R. (2021). Students' Understanding of the Derivative Concept in the Context of Mathematics for Economics. Journal für Mathematik-Didaktik, 42(1), 273305. https://doi.org/10.1007/s13138-020-00174-z

Fuentealba, C., Badillo, E., \& Sánchez-Matamoros, G. (2019). Identificación y caracterización de los subniveles de desarrollo del esquema de derivada [Identification and characterization of the development sub-levels of the derivative schema]. Enseñanza de las Ciencias, 37(2), 63-84. https://doi.org/10.5565/rev/ensciencias.2518

Giraldo, V., \& Carvalho, L. M. (2003). Local straightness and theoretical-computational conflicts: computational tools on the development of the concept image of derivative and limit. In 3rd Conference of the European Society for Research in Mathematics Education.

Gundlach, M. R., \& Jones, S. R. (2015). Students' understanding of concavity and inflection points in realworld contexts: Graphical, symbolic, verbal, and physical representations. In T. Fukawa-Connelly, N. E. https://doi.org/10.1007/s13138-020-00174-Z

Haghjoo, S., Reyhani, E., \& Kolahdouz, F. (2020). Evaluating the Understanding of the University Students (Basic Sciences and Engineering) about the Numerical Representation of the Average Rate of Change. International Journal of Educational and Pedagogical Sciences, 14(2), 111-121.

Hähkiöniemi, M. (2006). The role of representations in learning the derivative. University of Jyväskylä. https://doi.org/10.1016/i.jmathb.2021.100870

Heid, M. K. (1988). Resequencing skills and concepts in applied calculus using the computer as a tool.Journal for research in mathematics education, 19(1), 3-25. https://doi.org/10.5951/jresematheduc.19.1.0003 
Huang, C. H. (2011). Engineering students' conceptual understanding of the derivative in calculus. World Transactions on Engineering and Technology Education, 9, 209-214.

Hughes-Hallett, D., Gleason, A. M., McCallum, W. G., Connally, E., Flath, D. E., Kalaycioglu, S., ... , Tucker, T. W. (2017). Calculus: Single and multivariable (6th ed.). Hoboken: Wiley.

Jaafar, R., \& Lin, Y. (2017). Assessment for learning in the calculus classroom: A proactive approach to engage students in active learning. International Electronic Journal of Mathematics Education, 12(3), 503-520.

Johnson, H. L. (2010). Making sense of rate of change: Secondary students' reasoning about changing quantities. Unpublished doctoral dissertation. University Park,PA: The Pennsylvania State University.

Jones, S. R. (2017). An exploratory study on student understanding of derivatives in realworld, nonkinematics contexts. The Journal of Mathematical Behavior, 45, 95-110. https://doi.org/10.1016/j.jmathb.2016.11.002

Likwambe, B., \& Christiansen, I. (2008). A case study of the development of in-service teachers' concept images of the derivative. Pythagoras, 68, 22-31.

Maull, W., \& Berry, J. (2000). A questionnaire to elicit the mathematical concept images of engineering students. International Journal of Mathematical Education in Science and Technology, 31(6), 899-917. https://doi.org/10.1080/00207390050203388

Mirin, A. (2018). Representational Sameness and Derivative. North American Chapter of the International Group for the Psychology of Mathematics Education.

NCTM. (2000). Principles and standards for school mathematics. Reston, VA: The National Council of Teachers of Mathematics.

Oehrtman, M. (2009). Collapsing dimensions, physical limitation, and other student metaphors for limit concepts. Journal for Research in Mathematics Education,40(4), 396-426. https://doi.org/10.5951/iresematheduc.40.4.0396

Pino-Fan, L. R., Godino, J. D., \& Font, V. (2018). Assessing key epistemic features of didacticmathematical knowledge of prospective teachers: the case of the derivative. Journal of Mathematics Teacher Education, 21(1), 63-94. https://doi.org/10.1007/s10857-0169349-8

Rivera-Figueroa, A., \& Guevara-Basaldúa, V. (2019). On conceptual aspects of calculus: a study with engineering students from a Mexican university. International Journal of Mathematical Education in Science and Technology, 50(6), 883-894. https://doi.org/10.1080/0020739X.2018.1543812

Rodríguez-Nieto, C. A., Rodríguez-Vásquez, F. M., \& Moll, V. F. (2020). A new view about connections: the mathematical connections established by a teacher when teaching the derivative. International Journal of Mathematical Education in Science and Technology .https://doi.org/10.1080/0020739X.2020.1799254

Roorda, G., Vos, P., \& Goedhart, M. (2009, January). Derivatives and applications; development of one student's understanding. In Proceedings of CERME (Vol. 6).

Roschelle, J., Kaput, J. J., \& Stroup, W. (2012). SimCalc: Accelerating students' engagement with the mathematics of change. In Innovations in science and mathematics education (pp. 60-88). Routledge.

Roundy, D., Dray, T., Manogue, C. A., Wagner, J., \& Weber, E. (2015). An extended theoretical framework for the concept of the derivative. In T. Fukawa-Connelly, N. E. Infante, K. Keene, \& M. Zandieh (Eds.).

Samuels, J. (2017). A Graphical Introduction to the Derivative. Mathematics Teacher, 111(1), 48-53. https://doi.org/10.5951/mathteacher.111.1.0048

Sánchez-Matamoros, G., Fernández, C., \& Llinares, S. (2019). Relationships among prospective secondary mathematics teachers' skills of attending, interpreting and 
responding to students' understanding. Educational Studies in Mathematics, 100(1), 83-99. https://doi.org/10.1007/s10649-018-9855-y

Santos, A. G. D., \& Thomas, M. O. (2003). Representational ability and understanding of derivative. ERIC Clearinghouse.

Selden, A., Selden, J., Hauk, S., \& Mason, A. (2000). Why can't calculus students access their knowledge to solve non-routine problems. Issues in mathematics education, 8, 128153.

Sfard, A. (2008). Thinking as communication. Cambridge, England: Cambridge University Press.

Tall, D \& Vinner, S. (1981). Concept Image and Concept Definition in Mathematics with particular reference to Limits and Continuity. https://doi.org/10.1007/BF00305619

Tall, D. (2008). The transition to formal thinking in mathematics. Mathematics Education Research Journal, 20(2), 5-24. https://doi.org/10.1007/BF03217474

Thompson, P. W., \& Thompson, A. G. (1996). Talking about rates conceptually, Part II: Mathematical knowledge for teaching. Journal for Research in Mathematics Education, 27(1): 2-24. https://doi.org/10.5951/jresematheduc.27.1.0002

Weber, E., Tallman, M., Byerley, C., \& Thompson, P. W. (2012). Understanding the derivative through the calculus triangle. The Mathematics Teacher, 106(4), 274-278. https://doi.org/10.5951/mathteacher.106.4.0274

Zandieh, M. (2000). A theoretical framework for analyzing student understanding of the concept of derivative. CBMS Issues in Mathematics Education, 8, 103-127

Zandieh, M. J. (1997). The evolution of student understanding of the concept of derivative (Doctoral dissertation). http://hdl.handle.net/1957/15630 